\title{
Conserved roles of Distal-less and spalt in regulating butterfly melanic patterns
}

Jocelyn Liang Qi Wee ${ }^{1^{*}}$, Tirtha Das Banerjee ${ }^{1}$, Anupama Prakash ${ }^{1}$, Kwi Shan Seah ${ }^{1}$ and Antónia Monteiro ${ }^{1,2, *}$

1) Department of Biological Sciences, National University of Singapore

2) Yale-NUS College, Singapore

* ) Corresponding authors

\section{Abstract}

Simple spot patterns are proposed to be ancestral to more complex eyespot patterns found on the wings of butterflies. Two genes, Distal-less (DII) and spalt (sal), are known to be involved in two separate functions in establishing nymphalid butterfly eyespots: in the differentiation of their central signaling cells, or foci, necessary for eyespot ring formation, and in scale melanisation. However, little is known about the functions of these genes in the development of more primitive spot patterns. Here, we study the roles of $D I l$ and sal in the development of spots and other melanic wing patterns of the Indian cabbage white, Pieris canidia, a pierid butterfly. We examined the expression pattern of both genes in developing larval and pupal wings and explored their functions using the CRISPR/Cas9 system. In P. canidia, both DII and sal are expressed in the tips and along the margin of pupal wings, areas of future scale melanisation. Additionally, sal alone, is expressed in the future black spot patterns. CRISPR knockouts of DIl and sal showed that both genes are required for promoting melanic scales in the areas where they are expressed. Both DII and sal also function as repressors of the pteridine pigment pathway. We conclude that both genes share a conserved role in promoting scale melanisation, across pierid and nymphalid butterflies, but are unlikely to be involved in differentiating spot centers. The genetic and developmental mechanisms that set up the location of spots and eyespots are likely distinct and independently evolved in each lineage.

\section{Introduction}

Butterfly wings exhibit an astounding diversity of patterns shaped by their roles in thermoregulation (Kingsolver, 1985; Stoehr \& Goux, 2008), mate choice (Silberglied \& Taylor, 1978; Silberglied, 1984; Fordyce et al., 2002), and predator deterrence (Uésugi, 1996; Finkbeiner et al., 2014; De Bona et al., 2015). Of these wing patterns, eyespots, with their concentric rings of contrasting colors, are arguably one of the most well-studied patterns for their ecological functional roles in predator avoidance and in mate signaling (Robertson \& Monteiro, 2005; Stevens, 2005; Stevens et al., 2007; Merilaita et al., 2011; Prudic et al., 2015; Ho et al., 2016; Chan et al., 2021). 
Eyespots have also served as a model system in the study of the origin of novel traits. A study examining the phylogenetic distribution of eyespots across the Lepidoptera proposed that eyespots were homologous across nymphalids because they likely had a single origin close to the base of the clade (Oliver et al., 2012). A subsequent study suggested that eyespots replaced spot patterns that were already present in specific wing sectors (Oliver et al., 2014). Examining the origin of eyespots may thus benefit from investigating the development of spots in more basal lineages of butterflies, such as pierids.

Spots in pierids and eyespots in nymphalids show differences and similarities in the expression of a few candidate genes at different stages of wing development, as well as in cellular arrangements. At the late larval stage, several genes required for eyespot center differentiation in nymphalids, including the transcription factors Distalless and spalt, are absent from the presumptive spot centers of Pieris rapae butterflies (Monteiro et al., 2006; Saenko et al., 2011; Oliver et al., 2012; Connahs et al., 2019; Murugesan et al., 2021). Furthermore, these two genes are hypothesized to be part of, or downstream, of a morphogen set up by a reaction-diffusion mechanism. This mechanism is proposed to differentiate the eyespot central cells, also called the focal cells, from the surrounding cells in each wing sector bordered by veins (Connahs et al., 2019). These focal cells are more densely packed and slightly raised from the wing plane relative to other epidermal cells (Iwasaki et al., 2017). In pierids, however, no such reaction-diffusion mechanism has been proposed for spot center differentiation, and the cells at the center of these spots resemble cells elsewhere on the wing. At early pupal stages of development, however, both DII and sal proteins are present in future black scale cells in developing wings of nymphalids. In addition to eyespot focal cells, sal protein is also associated with melanic scale patterns in both the nymphalid Bicyclus anynana and in several pierids (Monteiro et al., 2006; Saenko et al., 2011; Oliver et al., 2012; Stoehr et al., 2013). Dll proteins, however, have only been associated with melanic patterns in nymphalids, such as $B$. anynana (Brakefield et al.1996; Monteiro et al. 2006).

CRISPR/Cas9 disruptions of both DIl and sal, and transgenic experiments in $B$. anynana showed that both genes are required to produce melanic scales but in slightly different ways. Both DII and sal are required for scale melanisation (Connahs et al., 2019). However, sal has an additional role of differentiating black scales by repressing another gene, optix, that is involved in the development of orange scales of nymphalid eyespots (Banerjee et al., 2021; Murugesan et al., 2021). Ectopic laserinduced expression of $D I I$ in the early pupa wing of $B$. anynana showed that DII is sufficient to activate the melanin biosynthesis pathway in the early pupal wing (Monteiro et al., 2013).

To date, no studies have managed to functionally identify the up-stream signals that activate $D I I$ and sal in the black disc of an eyespot. These signals are likely candidate long-range morphogens produced by the central signalling cells, the foci. 
Several promising candidates have been studied over the years: i) members belonging to the Wnt signalling gene family like wingless (Monteiro et al., 2006; Özsu et al., 2017), and ii) a signal transducer of the BMP pathway, mothers against decapentaplegic (smad) were previously shown to be expressed in eyespot foci (Monteiro et al., 2006), and RNAi against Wg led to smaller eyespots (Özsu et al., 2017). This is particularly exciting as in Drosophila, DIl is a target gene of both $d p p$ and $w g$ signalling in the establishment of the proximo-distal (PD) axis during limb and wing development (Cohen et al., 1993; Estella et al., 2008). Likewise, the expression domains of spalt are also strictly defined by $d p p$ signalling during the development of the Drosophila wing blade (de Celis et al., 1996; Barrio \& de Celis, 2004).

Given that both DII and sal proteins are associated with nymphalid eyespot foci, as well as other elements such a black scales and parafocal patterns along the wing margin of numerous nymphalid species (Monteiro et al., 2006; Zhang \& Reed, 2016; Connahs et al., 2019; Reed et al., 2020), here we ask whether these transcription factors have a similar role in establishing melanic wing patterns in a species belonging to a more basal butterfly lineage, the Pieridae. We also ask whether the same candidate morphogens suspected of setting up eyespot centers in nymphalid butterfly larval wings might be setting up spot centers in pierid larval wings or defining the expression of sal or DII in black scales, in pupal wings. To answer these questions, we used immunofluorescence and in-situ hybridisation to study the protein domains of DIl, sal, and armadillo (arm), a signal transducer of the Wnt signalling pathway, and the mRNA expression of $d p p$, a BMP ligand in Pieris canidia, the Indian cabbage white, $B$. anynana, and in a few other nymphalid species. We then studied the function of DIl and sal in P. canidia using CRISPR/Cas9 genome editing techniques. The goal of our study is to shed light on possible conserved or divergent mechanisms that differentiate spots and eyespots in two main lineages of butterflies. 


\section{Results}
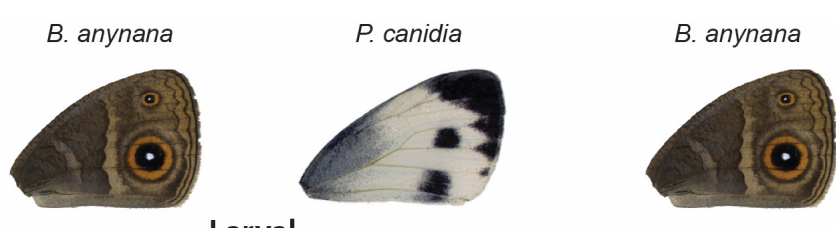

P. canidia

Larval

Pupal
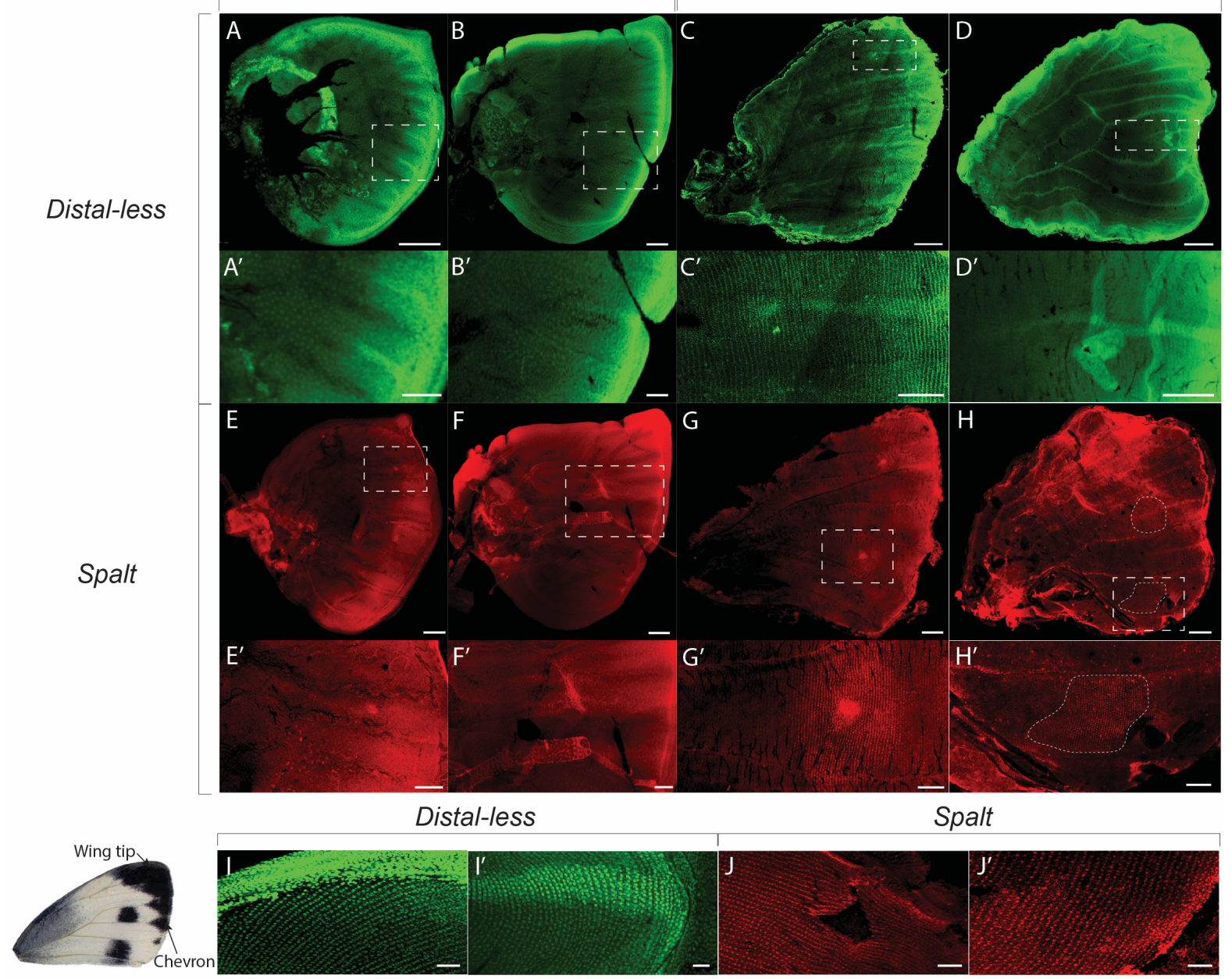

Chevron

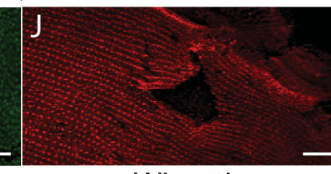

Wing tip

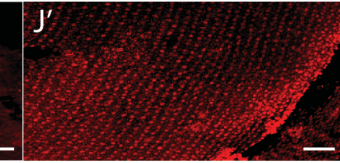

Figure 1. Immunostainings of Distal-less (green) and Spalt (red) proteins in Bicyclus anynana and Pieris canidia larval and pupal wings. $A, A$ ', B, B', C, C', $D$ and D') Distal-less protein is present in late fifth instar larval and 24-26h pupal wing discs. $\left.A, A^{\prime}, C \& C^{\prime}\right)$ In $B$. anynana larval and pupal wings, DIl is observed between veins as finger-like projections from the wing margin, ending with a discrete focus at the proximal tip of the fingers, that corresponds to the eyespot centres. In pupal stages of development, DIl becomes additionally observed in cells that correspond to the black scales of the eyespot pattern. B, B', D \& D') In P. canidia, intervein finger-like projections of Dll protein are observed but with no discrete foci at the tips of the fingers. $\left.E, E^{\prime}, F, F^{\prime}, G, G^{\prime}, H \& H^{\prime}\right)$. Spalt protein is present in late fifth instar larval and 24-26h pupal wings discs. E, E', G, \& G') In B. anynana, spalt protein is observed in eyespot foci during the larval stage. Like DIl, sal becomes additionally observed in the cells that map to the black scales in the eyespots during pupal wing development. F, F', H, \& H') In P. canidia, there is no cluster of cells in the middle of the spot pattern that is expressing higher levels of sal proteins in larval 
wings, and sal is present in the cells that map to the black scales in spots in $24 \mathrm{~h}$ pupal wings. I, I', J, J') Distal-less and sal proteins are also observed in cells that will become black scales located along the wing margin at both the wing tips and in the chevron patterns along the wing margin in $P$. canidia. Note the strong punctate nuclear staining of scale-building cells taken at 20x magnification. Scale bars for $(C$, $D, G$, and $H-500 \mu m) ;\left(A, B, B^{\prime}, C^{\prime}, D^{\prime}, E, F, G^{\prime}\right.$ and $\left.H^{\prime}-200 \mu m\right) ;\left(E^{\prime}\right.$ and F' -

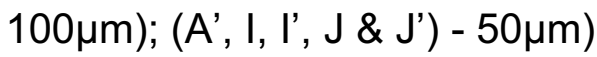

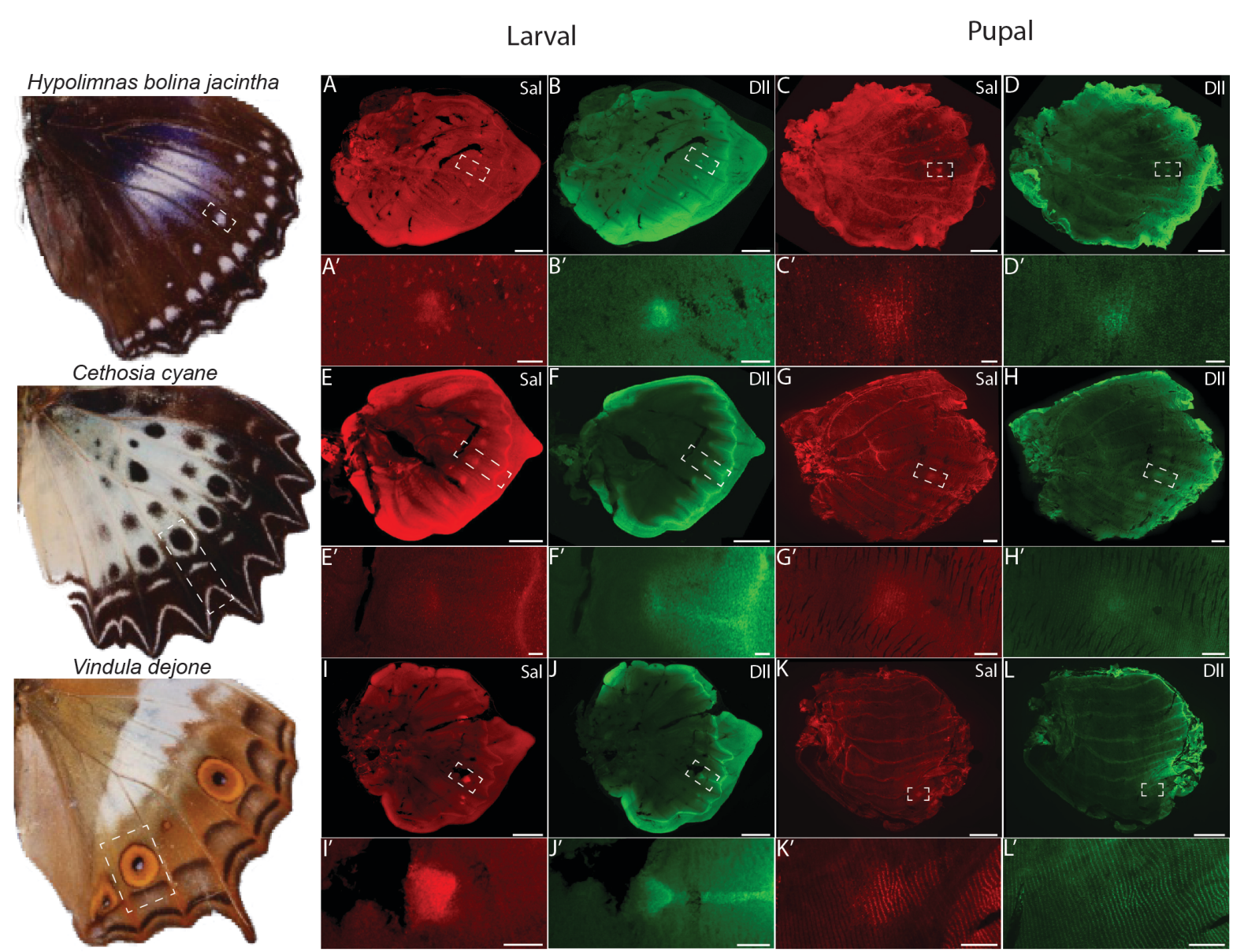

Figure 2. Immunostainings of Distal-less (green) and Spalt (red) in three other nymphalid species with spot and eyespot patterns. In all species surveyed here, both DII and sal proteins are present in spots and eyespot patterns in both late fifth

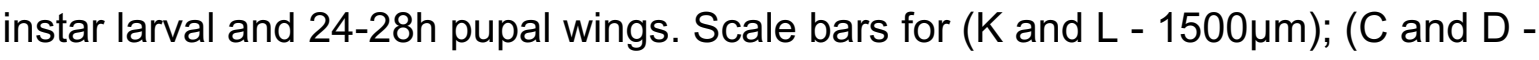

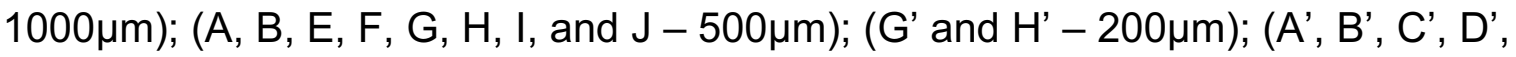

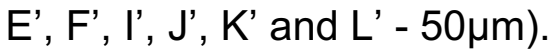

\section{Presence of Distal-less and Spalt proteins in $B$. anynana and $\boldsymbol{P}$. canidia}

We examined the distribution patterns of DIl proteins for both larval and $24 \mathrm{~h}$ pupal wings of $B$. anynana and $P$. canidia (Fig 1 ). Larval wing discs of both species showed strong levels of DIl along the wing margin, and in midline finger-like projections from the margin, between developing veins (Fig 1A \& 1A'). Levels of DIl protein were higher in a cluster of cells at the end of these fingers in $B$. anynana larval and pupal wings but not in $P$. canidia (Fig 1A \& Fig 1C). In P. canidia larval 
and pupal wings, DII levels continue to be high in mid-line projections in individual wing sectors (Fig 1B', D'). These findings are consistent with previous studies done in a closely related species, Pieris rapae (Reed \& Serfas, 2004; Monteiro et al., 2006). A novel observation, however, is that DIl is also present in areas along the wing margin containing the black chevrons, and in the wing apex, mapping to the areas of melanised scales at these two locations (Fig 1 I \& 1 l').

The presence of sal proteins was also examined for both species at the same time points in larval and pupal wings. In a similar manner to Dll, sal proteins were present in the eyespot foci in late larval wings of $B$. anynana (Fig 1E, E') but absent from spot centers in $P$. canidia (Fig, 1F, F'). In 24 h pupal wings, sal was additionally observed in the scale-building cells that map to the black scales of an eyespot (Fig 1G'). In P. canidia, sal was observed in the scale-building cells that map to all the densely melanised areas on the wing, including the black spots, the chevrons at the margin of the wing, and the apex of the wing (Fig 1 $\mathrm{H}^{\prime}, 1 \mathrm{~J} \& 1 \mathrm{~J}$ '). However, spot centers did not have elevated levels of sal, nor did these central cells appear distinct from surrounding spot cells, as they do in eyespots. These results are similar to those previously described for other pierids (Monteiro et al. 2006; Stoehr et al., 2013).

The protein localizations of DII and sal in three other nymphalid species was like those observed in B. anynana. DIl and sal were present in the focal cells of future eyespots and spots (of Hypolimnas bolina jacintha) during the larval stage (Fig 2). This pattern persisted in $24 \mathrm{~h}$ pupal wings but the two proteins were additionally present in a few surrounding scale-building cells that map to black pattern elements in an eyespot or spot. The simple white spots of Hypolimnas bolina are likely equivalent to central cells of an eyespot that have become reduced to a single ring/spot of color with just a few black cells around them. 


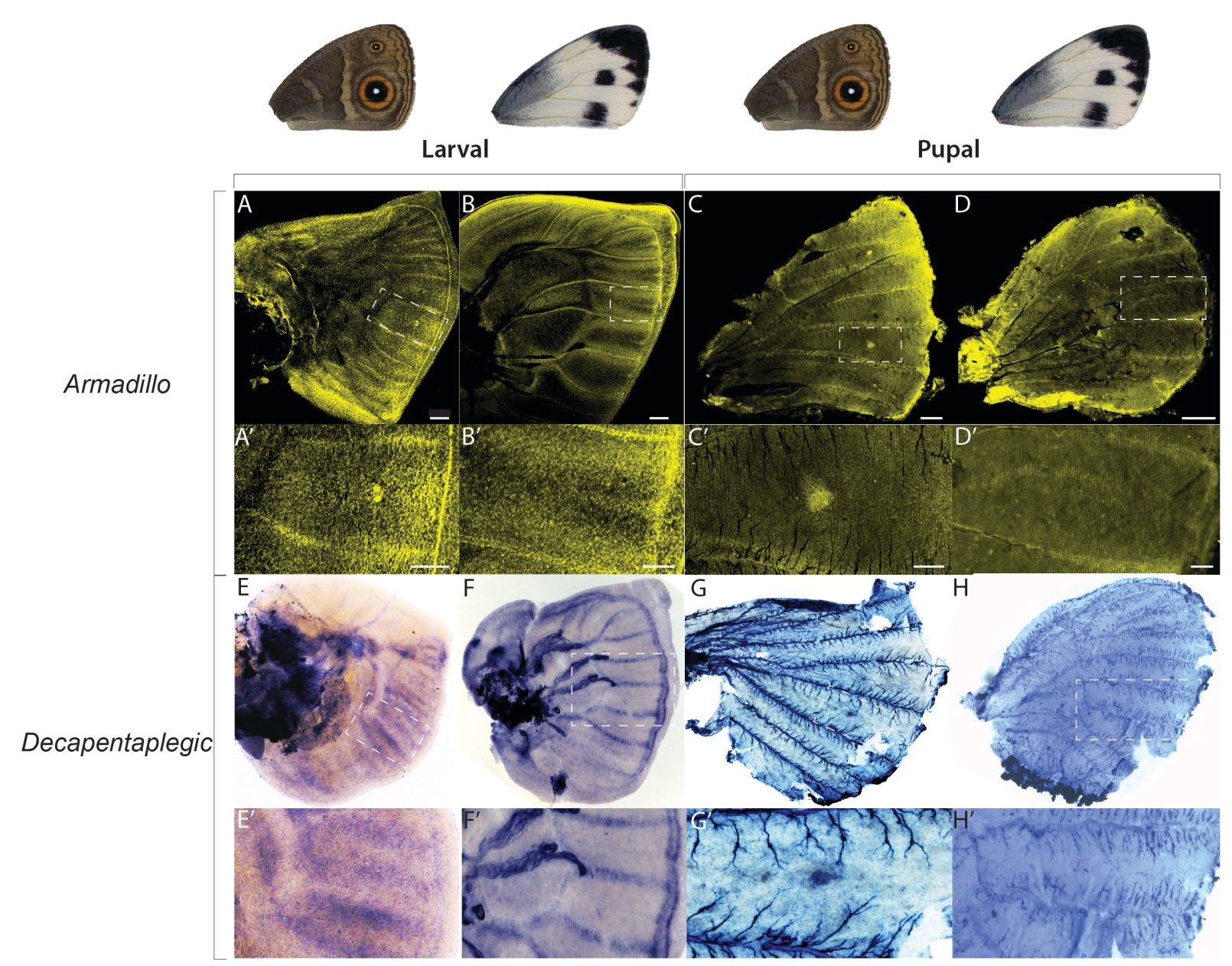

Figure 3. Expression of armadillo (arm) protein, and decapentaplegic (dpp) mRNA in Bicyclus anynana and Pieris canidia larval and pupal wings. A, A', B, $B^{\prime}, C, C^{\prime}, D$ \& D') Distribution of arm protein in late fifth instar larval and 20h pupal wings. $\left.A, A^{\prime}, C \& C^{\prime}\right)$ In $B$. anynana, arm is present along the wing margin and in eyespot foci in both larval and pupal wings. B \& B') In $P$. canidia larval wings, arm is present between veins in finger-like projections, in a similar pattern to that of Distalless. D \& D') arm is not present in the black spots of $P$. canidia in $20 \mathrm{~h}$ pupal wings. $\mathrm{E}, \mathrm{E}^{\prime}, \mathrm{F}, \mathrm{F}^{\prime}, \mathrm{G}, \mathrm{G}^{\prime}, \mathrm{H} \& \mathrm{H}^{\prime}$ ) localization of $d p p m R N A$ transcripts in late fifth instar larval, $18 \mathrm{~h}$ pupal wings (B. anynana) and $18 \mathrm{~h}$ pupal wings $(P$. canidia). E, E', G, \& $\left.G^{\prime}\right) d p p$ is expressed in areas flanking the veins in $B$. anynana larval wing discs and is absent from eyespot foci at this stage. $d p p$ is expressed in eyespot foci in $18 \mathrm{~h}$ pupal wings. F \& F") $d p p$ is expressed strongly along veins and along the border lacuna in $P$. canidia larval wings. $\mathrm{H} \& \mathrm{H}^{\prime}$ ) $d p p$ is not expressed in the center of spot patterns in $18 \mathrm{~h}$ pierid pupal wings. The wing used for $d p p$ in-situ hybridisation in Fig $1 G$ and $1 G$ ' is a $B$. anynana hindwing.

\section{Presence of armadillo (arm) and expression of decapentaplegic (dpp) in $B$.} anynana and $P$. canidia

In the Drosophila wing margin, $D / l$ is a downstream target of Wnt signalling, whereas in the center of the wing, sal is a target of Dpp signalling. To investigate whether Wnt and Dpp signalling could be upstream of the melanic patterns in $P$. canidia, we 
performed immunostainings targeting the protein armadillo (arm), a signal transducer of canonical Wnt signalling, and performed in situ hybridizations with a probe against $d p p$. We found arm present in the wing margin and in finger-like patterns from the wing margin in both $B$. anynana (as previously described in Connahs et al. 2019) and $P$. canidia (Fig 3A \& 3B). However, arm is present in the eyespot centers in $B$. anynana but not in spot-like patterns in $P$. canidia during both larval and pupal stages (Fig 3A', 3B', 3C' \& 3D'). This suggests that Wnt signaling is stable and active in $B$. anynana eyespot centers but not in $P$. canidia spot centers. In $B$. anynana, $d p p$ is present in cells flanking the veins and also along the anterior-posterior (AP) boundary (as previously described in (Connahs et al., 2019; Banerjee \& Monteiro, 2020b)), and later in eyespot centers in 16h pupal wings (Fig 3E \& 3G). In P. canidia larval wings, $d p p$ is expressed strongly along the veins and the border lacuna, parallel to the wing margin. No $d p p$ was detected in areas mapping to the spot pattern in $17 \mathrm{~h}$ pupal wings (Fig $3 \mathrm{~F} \mathrm{\&} 3 \mathrm{H}$ ). 

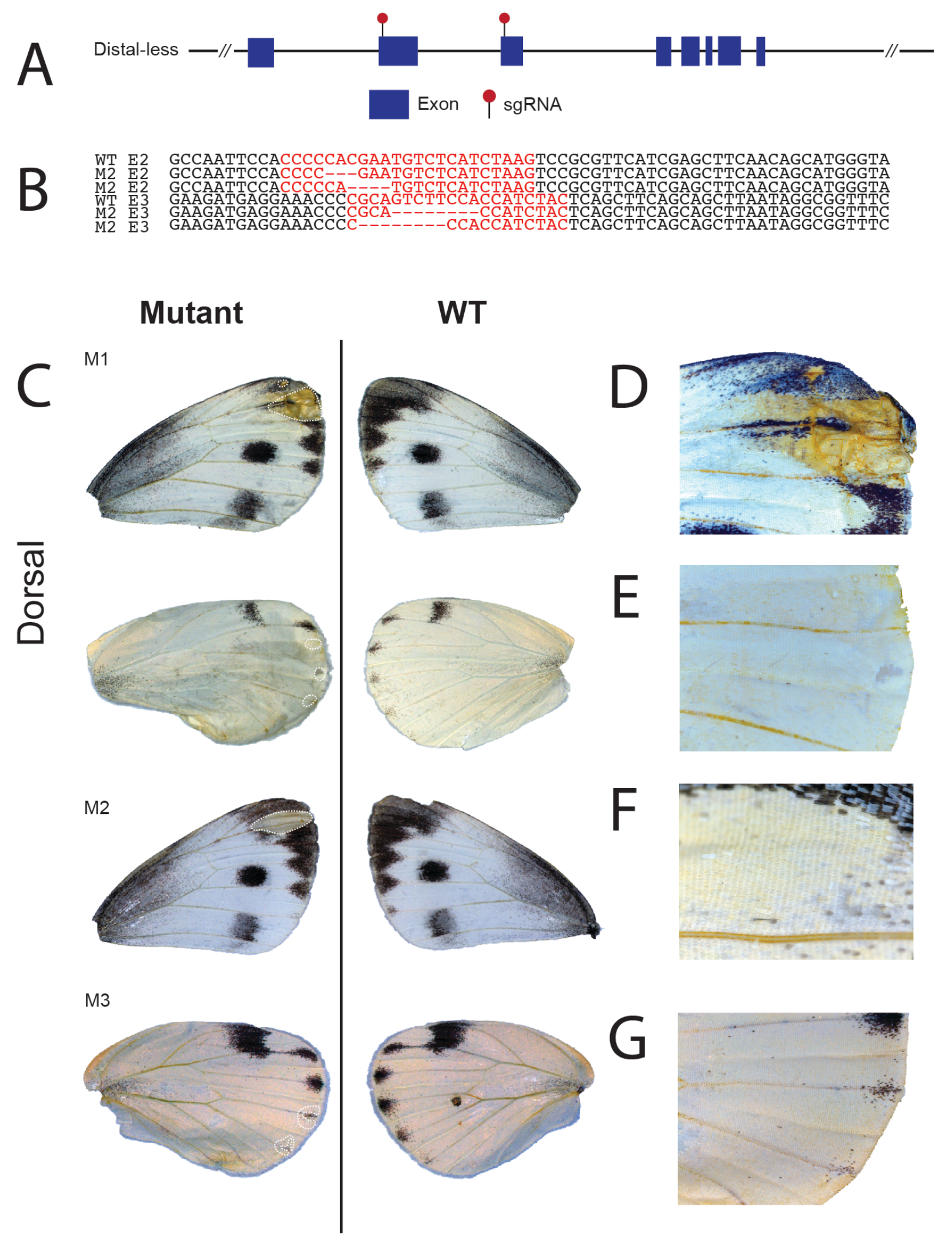

Figure 4. Distal-less functions in the development of wing margin melanic scale development in $\boldsymbol{P}$. canidia. A) Structure of the Distal-less locus and location of the two sgRNAs used to disrupt the locus in exons 2 (E2) and exon 3 (E3) (red pins). B) DIl crispants had indels in both E2 and E3 that were detected using NextGeneration sequencing. C) Various Distal-less crispants generated through CRISPR/Cas9 of both E2 and E3. Phenotypes include D \& F) missing black scales in 
the wing apex, and $E \& G$ ) transformation of black scales in chevron areas to white scales. (D-G) Close-up of mosaic area affected by the CRISPR knock-out experiments. Crispants shown here were affected by disruptions in both Exons 2 and 3.

To test the function of $D / l$ in spot development and melanisation, we targeted both exons 2 and 3 using the CRISPR/Cas9 system (Fig 4A). Consistent with the immunostaining results for DII, melanic wing patterns located along the wing tip and in chevrons along the wing margin were disrupted (Fig 4C). The black spots were not affected. In the affected areas, black scales were transformed into white scales. In two of the crispants, both ground and cover scales were missing from the affected regions (Fig 4D \& 4F). 

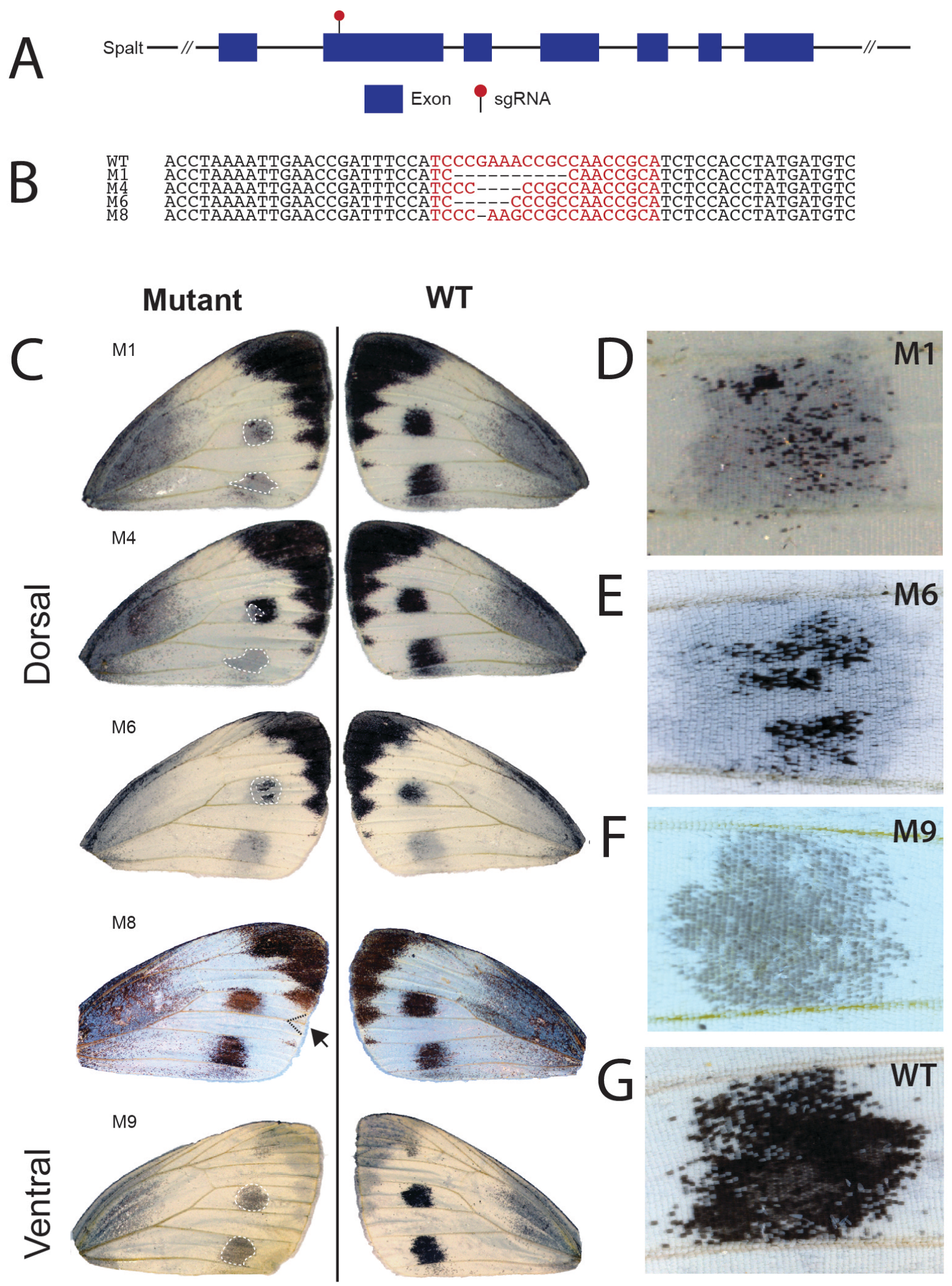

Figure 5. spalt functions in black scale development in $\boldsymbol{P}$. canidia. A) Structure of the spalt locus and area targeted by the sgRNA (red pin). B) spalt crispants had indels in the target region that were detected using Sanger sequencing. C) Various spalt crispants (mosaic mutants) generated through CRISPR/Cas9. Phenotypes include missing spots or missing black scales in spots, disrupted Cu2 veins, missing 
black chevrons located along the wing margin (M8), and less melanised spots (M9). D-F) Close up of mosaic areas affected. G) Close up of black spot pattern in wildtype $P$. canidia.

To test the function of sal in spot development and in scale melanisation, we targeted exon 2 with the CRISPR/Cas9 system. The resulting mosaic phenotypes support a role for sal in scale melanisation in the spots, wing tips, and chevrons along the wing margin. We observed missing spots on both dorsal and ventral surfaces of forewings, fragmented spots, and a missing black wing marginal chevron in a single individual (Fig 5C, M8). Black scales in these areas were transformed into white scales. In addition, we saw one individual with less melanised scales (Fig 5C, M9).

Individual scales of DIl and sal mutants and wild-type butterflies were then closely examined using Scanning Electron Microscopy (SEM) to look for any changes in scale structure that might be under the regulation of either gene. Wild-type black scales had little to no pigment granules present, in contrast to white scales (Fig 6A). In both DIl and sal mutants, black scales that converted into white contained dense rows of ovoid-like pigment granules deposited along the cross-ribs $(6 \mathrm{~B}, \mathrm{C})$, resembling Wt white scales. The scales of the spalt crispant that displayed less melanised scales in the black spot region (Fig 6D) were intermediate in color and in morphology - the windows were not completely open and remnants of upper lamina were observed along the crossribs as compared to Wt black scales (Fig. 6D). Pigment granules are also scattered within the scale lumen. 
A

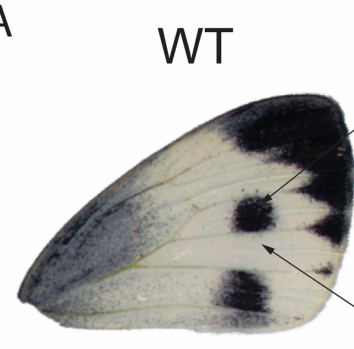

C

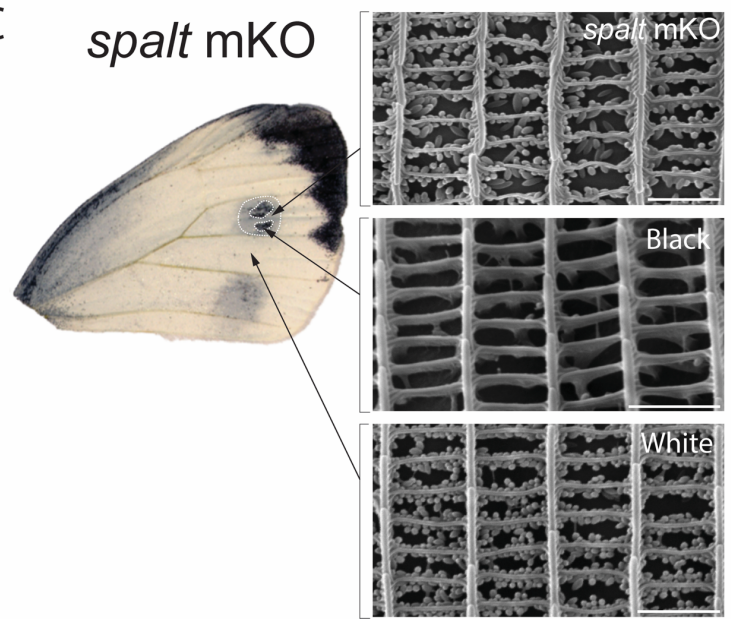

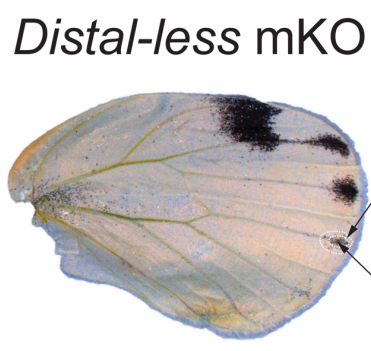

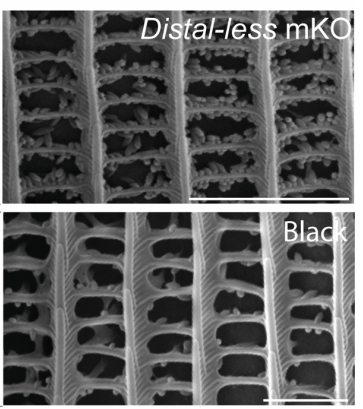

D
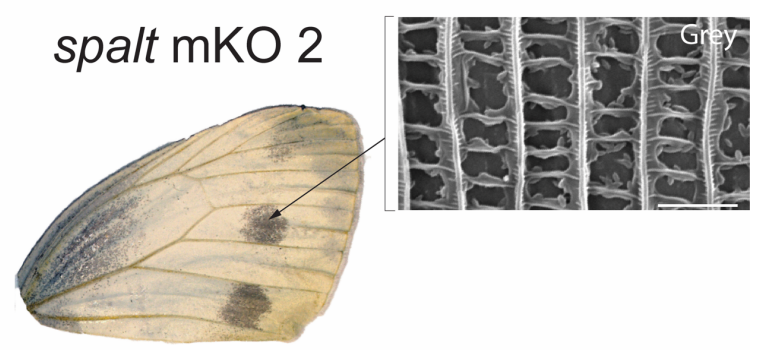

Figure 6. Melanised scales that become white scales acquire pterin pigment granules visible under scanning electron microscopy (SEM). Individual $P$. canidia scales were removed from wild-type black and white regions, as well as from spalt $\mathrm{mKO}$, and Distal-less mKO affected regions. A) SEM images of a black scale and a white scale removed from the forewing of wild-type $P$. canidia. Close-up of the black scale showing no pigment granules present along the cross-ribs of the scale. Pigment granules are present in great numbers in white scales. B) SEM images of black scales and white scales removed from a DIl crispant. This crispant had greatly reduced spots on its hindwing. Scales that lost melanin pigments showed a morphology resembling that of wildtype white scales. C) SEM images of black and white scales removed from a spalt crispant. The SEM image labelled as spalt $m K O$ showed a close-up view of a scale (originally black) removed from the CRISPR/Cas9 mosaic knockout area. Black scales converted into white scales with pigment granules, resembling those of wild-type white scales. D) SEM images of a spalt mutant that displayed an intermediate scale phenotype with less melanised scales in the black spot region. The morphology of these grey scales resembles that of WT black scales but windows of these scales were not fully opened and there remains residues of the upper lamina. Scale bars: $2 \mu \mathrm{m}$

\section{Discussion}

Most of the work done on unravelling the genetics of butterfly wing patterns has remained overwhelmingly focused on nymphalid butterflies. However, we do not know if genes involved in the development of nymphalid-specific wing patterns, such 
as eyespots, also play a role in the development of other more primitive patterns in other butterfly lineages. Here, we present three main findings. First, we provide functional evidence for a deeply conserved role of two transcription factors, Distalless and spalt, as being required for melanin pigment production in both pierids and nymphalids. Second, we illustrate the possible dual role that both DII and sal play in repressing the development of pterin pigment granules, located within individual scales of pierids butterflies, and in the activation of the melanin biosynthesis pathway. Lastly, we propose that unlike eyespot center differentiation, spot differentiation does not depend on the expression of either D/l or sal at the center of the pattern during the larval stages of development.

Previous research suggested that eyespots may have derived from simpler spot patterns (Oliver et al., 2014), but genes previously associated with eyespot patterns were not found in spots, with the exception of sal (Monteiro et al., 2006). Here we show that both DII and sal have deeply conserved roles in regulating melanic patterns in lepidopteran wings, that predates the divergence of nymphalid and pierid butterflies (Fig 7). sal knockouts showed disrupted black spots and marginal markings, whereas DII knockouts showed reductions of melanic patterns located along the wing tip and wing margins of both forewings and hindwings. We propose that the developmental mechanism underlying the evolution of melanic spots and eyespots is homologous in this context, with the same genes performing a similar function i.e., differentiating black scales, in both traits. We still do not know how melanin pathway genes are being regulated by either DIl or sal nor do we know the upstream signal(s) that both genes are responding to in lepidopterans. Future studies could try to unravel the regulatory connections between DII and sal and downstream melanin biosynthesis genes. 


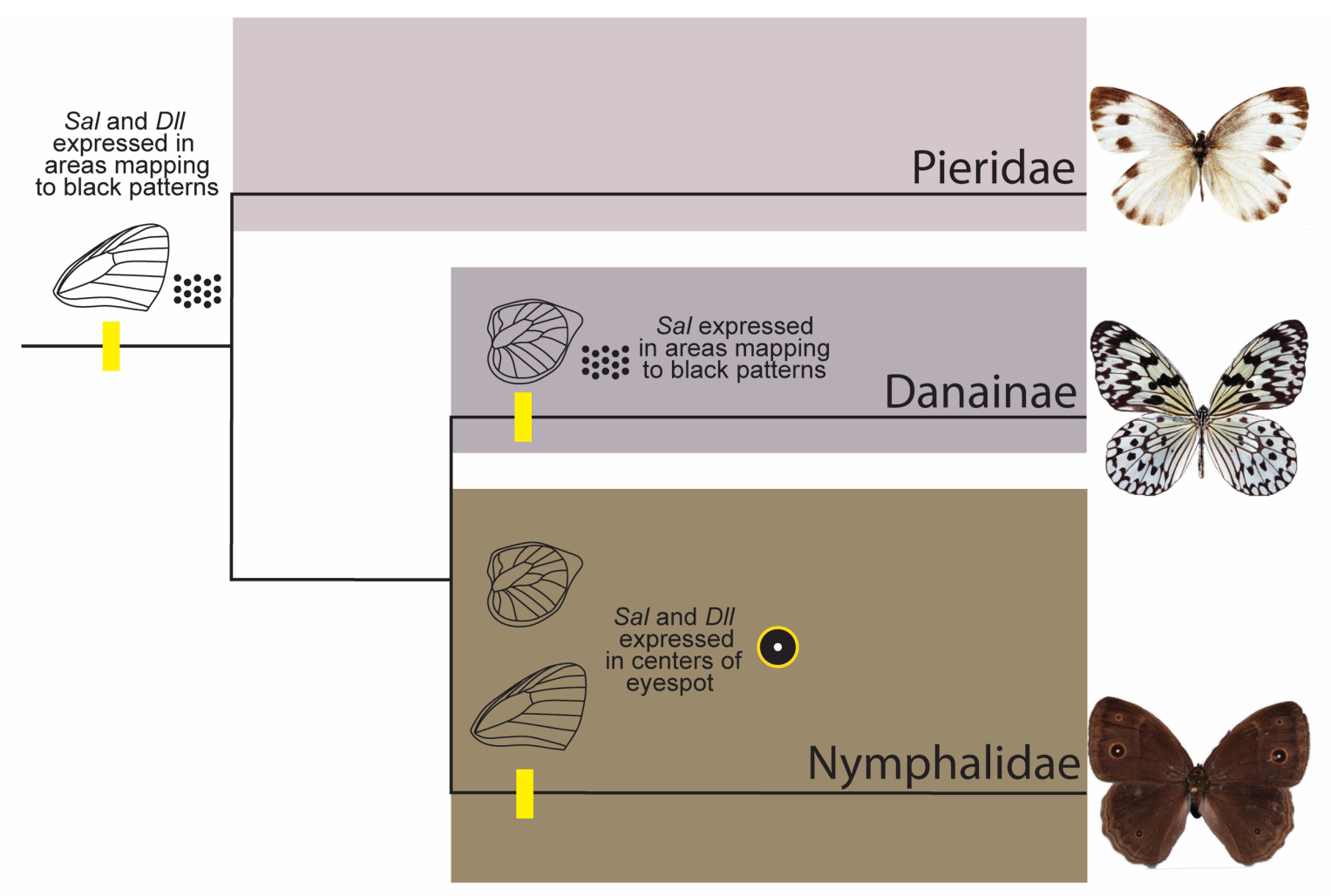

Melanin production ::::: Focal determination of eyespots

Larval wing

Pupal wing

Expression of gene

Figure 7. The evolution of novel expression domains and functions of Distalless and spalt mapped onto a simplified phylogeny of butterflies. Expression of $D I l$ and sal associated with black scales in the pupal stage is mapped to a branch ancestral to the divergence of pierid and nymphalid butterflies. Because sal is expressed in late larval wing discs in areas corresponding to black wing spot elements in Idea leuconoe (Danainae; (Bhardwaj et al., 2020)), the origin of expression of that gene in the larval stage was mapped independently in the lineage leading to Danainae. In nymphalids, both DII and sal likely gained derived roles in the differentiation of eyespot centers.

Interestingly, while both genes are required for the formation of black marginal chevrons and wing tips, sal alone is required for the development of wing spots in $P$. canidia. We postulate that $D / l$ is likely working upstream of sal in areas where the two genes are co-expressed, but not in the black spot area of $P$. canidia. The regulatory interaction between sal and $D / l$ in setting up melanic wing patterns has been inferred from mutants and from functional work in $B$. anynana. In wildtype $B$. anynana, both spalt and DII are co-expressed in the black scales of an eyespot. $A$ recent study showed that sal is a repressor of optix, a gene that is expressed in the orange scales of eyespots (Banerjee et al., 2021). Disruption of sal led to loss of the black scales and to their replacement by optix-expressing orange scales (Banerjee et al., 2021; Murugesan et al., 2021). DIl, on the other hand, is required for melanin pigment production in the black scales and in background brown wing scales (Connahs et al., 2019). Further, in Goldeneye B. anynana mutants, which had its 
black scales replaced by orange scales within the eyespot pattern, DIl proteins persisted while sal proteins were absent (Brunetti et al., 2001). This suggests that DII is upstream of sal and that, at least for $B$. anynana, both $D I l$ and sal are required for the development of black scales in eyespots. Recent work showed that DII upregulates sal in the eyespot centers of $B$. anynana during the larval stage, whereas sal does not up-regulate DII (Murugesan et al., 2021). This circuit might also be deployed during the pupal stage in the black disc region of nymphalid eyespots and in the tips and black chevrons of $P$. canidia wings, but additional work will be necessary to confirm this.

Similarly to a previously reported gene, optix (Zhang et al., 2017), spalt may be functioning as a 'switch' gene that represses the pterin biosynthesis pathway (white) while activating the melanin biosynthesis pathway (black). If spalt was purely an upstream activator of genes involved in melanin synthesis, we would expect to see scale morphology of mutant scales resembling those of the flanking black scales that were unaffected by the CRISPR/Cas9 knockout. However, when spalt mutant scales were examined using SEM, we observed numerous pigment granules densely arranged along the cross-ribs, closely resembling the structures found in wildtype white scales. White scales of pierid butterflies differ from those of other butterfly species in that the cross-ribs of each scale are attached to many spheroidal beads (Ghiradella et al., 1972; Stavenga et al., 2004; Wilts et al., 2017). These beads contain leucopterin, a class of heterocyclic pigment that absorbs exclusively in the ultraviolet range. When coupled with the strong light-scattering properties of these beads, leucopterin filled granules cause scales to appear white (Wilts et al., 2011). Our examination of the poorly melanised spot that was likely derived from a hypomorphic allele of sal, or perhaps a heterozygote crispant clone, suggests that intermediate scale colors (grey) and morphologies are possible (Fig 7D). This mutant suggests that intermediate levels of sal protein might be insufficient for complete downregulation of the pteridine pathway and for complete up-regulation of the melanin pathway.

DIl mutant clones displayed two phenotypes, loss of all scales and a change in scale color from black to white. The loss of both cover and ground scales, lends further support to butterfly scales being a derived form of a sensory bristle (Galant et al., 1998) that requires DIl for its development (Panganiban, 2000). This corroborates a previous finding by Connahs et al. (2019) whereby loss of scales was also observed in $D / l$ crispants in $B$. anynana. The transformation of black to white scales may be connected to hypomorphic alleles of DIl, or perhaps to heterozygote crispant clones. It is tempting to speculate that like sal, DII might also regulate two different pigment pathways simultaneously. However, it is more likely DIl was working upstream of sal in the wing marginal patterns and that the knocking out DIl resulted in the downregulation of sal, leading to the formation of ectopic pigment granules. This is also supported by the observation that knockouts of sal alone, in spots, produces the scale color switch phenotype. 
Thus, we propose that prior to the split of nymphalid and pierids butterflies, both DII and sal had roles in activating downstream melanin pigment enzymes to produce melanic scales. These transcription factors were regulating the development of melanic wing patterns on different areas of the wings, with sal required for black scale differentiation in some domains, and DIl required for the same process in other domains, perhaps performing this function via the up-regulation of sal.

However, after the divergence of nymphalids from pierids, nymphalid eyespot evolution relied on the novel larval expression of $D I l$ and sal in the foci at the tips of intervein midlines. This novel expression may have taken place through a gradual increase of $D / l$ expression that promotes a stable expression of $D / l$ at the foci via a reaction-diffusion mechanism (Connahs et al. 2019; Fig 8). Higher DIl levels, in turn, may be dependent on Wnt and dpp signals which become anti-colocalized at late stages of eyespot focus differentiation, again via the same reaction-diffusion process (Connahs et al., 2019)(Fig 8). In P. canidia, armadillo protein patterns were quite similar to those observed in $B$. anynana but again, no arm foci were detected at the end of the intervein fingers (Fig 3B'). The $d p p$ pattern was also different in $P$. canidia and was not anti-colocalized with the arm pattern (Fig 3F'). This suggests that a reaction-diffusion mechanism like that proposed for $B$. anynana is not taking place in $P$. canidia during mid larval development.

The mechanism that sets up spots and black discs of color around eyespots, during the pupal stage, may also be distinct. During early pupal stages, no discernible arm nor $d p p$ signals were observed in spot centers (Fig 3D' \& 3H') as they were in eyespot centers (Fig. 3C', 3G'). It is possible that sal in $P$. canidia may be responding to a gradient of BMP ligands such as $d p p$ that is emanating from the wing margin. High levels of $d p p$ expression were present along the wing margin of $P$. canidia larval wings (Fig 3F'), but not in B. anynana (Fig 3E'). Thus, we speculate that the role of $D I l$ and sal in establishing nymphalid eyespot foci is novel and derived as compared to pierid spot development.

This derived role of $D I l$ and sal as eyespot center organisers is supported by the fact that in late larval wings, the expression of both DII and sal in the presumptive eyespot centers in nymphalid species is essential for eyespot development (Zhang \& Reed, 2016; Connahs et al., 2019; Murugesan et al., 2021). Knockouts of DIl and sal in $B$. anynana that affected cells located in the eyespot center always led to the complete disappearance of an eyespot (Connahs et al., 2019; Murugesan et al., 2021). The expression of both genes, however, is absent from spot centers in pierid species during the larval stage (Reed \& Serfas, 2004; Stoehr et al., 2013).

Correspondingly, when scale cells located in the spot center were affected in $P$. canidia spalt knockout mutants, we did not observe entire spots disappearing. Instead, scattered areas of the spot retained melanised scales (Fig 5C). 
The developmental mechanism of pierid spot differentiation is not yet fully understood. Pierid spots may rely on differentiated cells at their center to signal to surrounding cells to differentiate the complete spot pattern, as previously proposed (Stoehr et al. 2013). Alternatively, spots may be fragments of an anterior-posterior banding system that relies instead on both activator or inhibitory signals spreading from the wing margin and wing veins (Monteiro et al. 2006). Regardless of the exact mechanism of spot development, our current experiments show that spots do not rely on $D I l$ and sal being expressed at their center during the larval stages to differentiate.

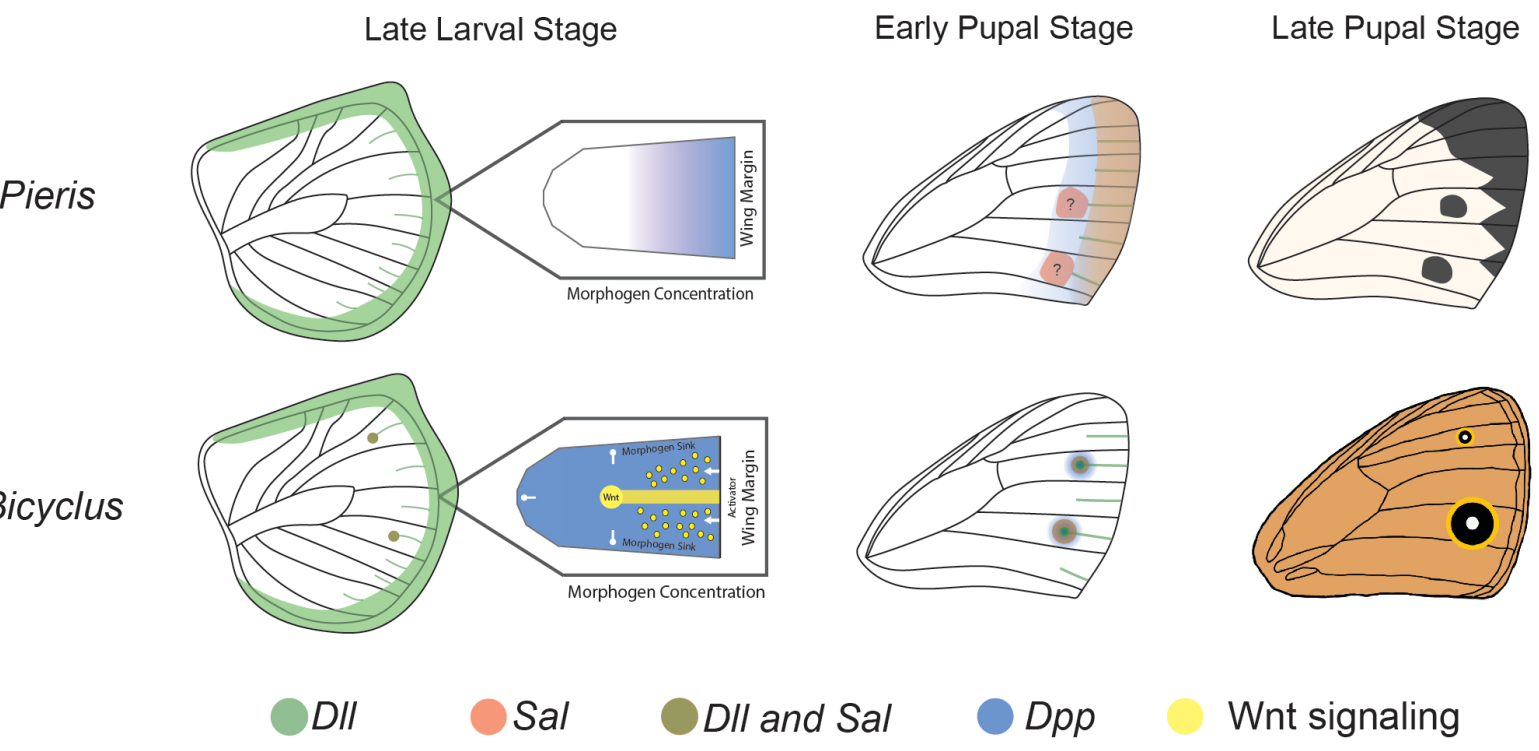

Figure 8. A model for the roles of Distal-less and spalt in pierid spot and nymphalid eyespot development. In late larval wing discs of $B$. anynana, both DII (green) and sal (red) are co-expressed at high levels in the center of eyespots. However, in late larval wing discs of $P$. canidia, DIl and sal are not expressed in spot centers. Only $D I I$ is expressed in mid-line fingers encroaching inwards from the wing margin. Eyespot centers in $B$. anynana are likely established through a reaction diffusion mechanism involving Wnt and BMP signaling (Connahs et al., 2019). The absence of arm proteins and $d p p$ expression in $P$. canidia spot centers suggests that spots may not develop through the same mechanism. In nymphalid eyespots, DII and sal respond to signals emanating from the foci. However, in early pupal stages, both arm and $d p p$ are absent in spot centers. There may be no central signaling cells that are present in spot patterns that are activating downstream genes (i.e sal). An alternative explanation would be that sal may be responding to a gradient of BMP ligands and a band of an unidentified inhibitory molecule (orange) secreted from the wing margin to give rise to the black markings of $P$. canidia during late pupal development. 


\section{Conclusion}

Simpler monochromatic spot-like patterns have been proposed to be a primitive form of more complex eyespot patterns. In this study, we tested the function of two transcription factors expressed in nymphalid eyespots, DIl and sal, in a basal butterfly lineage with primitive spots and other melanic patterns on its wings, $P$. canidia. Our work suggests that each transcription factor is required for activating distinct melanic elements in this species, including the spots, but these genes have likely no role in positioning spots on the wing. This suggests that the mechanism of melanin pathway regulation is shared between both spots and eyespots but the mechanism of setting up the position of these two pattern elements might have independently evolved in each lineage. Future work involving functional knockouts of other candidate genes will be able to shed more light on spot development and its connections with eyespot development.

\section{Materials and methods}

\section{Animals}

Pieris canidia used in this study were the descendants of wild-caught individuals from Singapore. Larvae were fed on potted Brassica chinensis var. parachinensis plants and adults on $10 \%$ sucrose solution. Bicyclus anynana larvae were fed on potted corn and adults on mashed banana. Both species were reared at $27^{\circ} \mathrm{C}$ and at $60 \%$ humidity under a 12:12h light/dark photoperiod. All other species of butterflies used for comparative immunostainings work were reared at Entopia, a butterfly farm (Penang, Malaysia) under outdoor conditions.

\section{Immunostainings}

Immunostainings were performed on $5^{\text {th }}$ instar larval wings and $16-30 \mathrm{~h}$ pupal wings dissected based on a protocol previously described by (Banerjee \& Monteiro, 2020a) in 1 XPBS at room temperature. Wings were fixed with $4 \%$ formaldehyde for 30 mins, washed with $1 \times$ PBS for four times at 10 mins, and transferred to $2 \mathrm{ml}$ tubes filled with block buffer for blocking at $4^{\circ} \mathrm{C}$ for up to several months to reduce non-specific binding of the antibodies. Wing discs were then incubated in primary antibodies against Distal-less (1:200, mouse, a gift from Grace Boekhoff-Falk), and spalt (1:10000, guinea-pig Sal GP66.1) overnight at $4^{\circ} \mathrm{C}$, washed with multiple rounds of wash buffer, and stained in secondary antibodies anti-mouse AF488 (Invitrogen, \#A28175) and anti-guinea pig AF555 (Invitrogen, \#A-21435) at a concentration of 1:500. Stained wings were then washed with multiple rounds of wash buffer, away from light, and mounted on glass slides with an in-house mounting media. Images of the wings were taken with an Olympus FV3000 Confocal Laser Scanning Microscope. All buffer compositions are summarised in Table S2.

\section{Whole-mount in-situ hybridisation}

In-situ hybridisations were performed on early to late $5^{\text {th }}$ instar larval wings and 16 $18 \mathrm{~h}$ pupal wings dissected in $1 \mathrm{xPBS}$ at room temperature to prevent the crumpling of 
wings. The wings were fixed with $4 \%$ formaldehyde in PBST for 30 mins, digested with $1.25 \mu$ l of Proteinase-K in $1 \mathrm{ml}$ of $1 \mathrm{x}$ PBST for 5 mins on ice. The digestion reaction was stopped with a $2 \mathrm{mg} / \mathrm{ml}$ glycine solution in 1X PBST and followed with 3 washes of $1 \mathrm{X}$ PBST. Larval wings were removed from ice briefly for 5 mins and placed right back on ice to induce 'puffing' of the peripodial membrane for easier removal of the membrane using fine tip forceps. After removing the peripodial membrane, the wings were transferred to increasing concentrations of prehybridisation buffer in 1 X PBST and incubated at $60^{\circ} \mathrm{C}$ for at least $1 \mathrm{~h}$ in prehybridisation buffer. Incubated wings were hybridised at $60^{\circ} \mathrm{C}$ with the probe $(100 \mathrm{ng} / \mathrm{ml})$ in a hybridisation buffer for $16-24 \mathrm{~h}$. The next day, after incubation with the riboprobe, wings were washed with pre-hybridisation buffer for $5 \times 10 \mathrm{mins}$ at $60^{\circ} \mathrm{C}$. The wings were then brought back to room temperature and transferred to $1 \mathrm{x}$ PBST gradually. 1x PBST was used to wash the wings for $2 \times 5 \mathrm{mins}$, and wings were subsequently transferred for blocking for $1 \mathrm{~h}$. Anti-digoxygenin was diluted in block buffer at a ratio of 1:3000 for incubation with the wings for $1 \mathrm{~h}$. Once completed, the wings were washed with block buffer for $5 \times 5$ mins on a rotary shaker and transferred to an alkaline phosphatase buffer containing NBT-BCIP. Wings were left to incubate in the dark to develop color signal to the required intensity. A Leica DMS1000 microscope was used to image the stained wings. All buffer compositions are summarised in Table S3.

\section{CRISPR-Cas 9}

Knock-outs of the genes $D I l$ and sal in $P$. canidia, were generated using the methods outlined in a previously published protocol (Banerjee \& Monteiro, 2018). Single guide RNAs (sgRNAs) targeting the genomic regions of exons 2 and 3 of DIl and exon 2 of sal were designed using the webtool CHOPCHOP (Labun et al., 2019). For the gene sal, a total of 575 embryos were injected with a mixture containing $300 \mathrm{ng} / \mu \mathrm{l}$ of sgRNA (one guide) and 600ng/ $\mathrm{ll}$ of Cas9 protein (NEB, M0641) while for DIl, 357 embryos were injected with a mixture containing $100 \mathrm{ng} / \mu \mathrm{l}$ of sgRNAs (2 guides) and $300 \mathrm{ng} / \mu \mathrm{l}$ of Cas9 protein (Table S4).

Wild-type $P$. canidia laid eggs on a piece of parafilm that was wrapped around a small container that had its top covered with a piece of fresh cabbage leaf. The container was placed within the butterfly cage for up to 6 hours at a time to maximise the number of eggs collected. The parafilm and leaf were then removed from the container and transferred to a petri-dish for injection with the Cas9 injection mixture. Pieces of moist cotton wool were placed in each petri-dish post injection to avoid desiccation of injected eggs. Hatchlings were then directly transferred to Brassica $s p$ plants and reared to adult eclosion. Upon emergence, the butterflies were frozen immediately in separate glassine envelopes and examined under the microscope for asymmetrical (left-right wing) phenotypic defects. Genomic DNA was isolated from the affected mosaic areas from CRISPR mutants, and indels were identified through Sanger and NGS sequencing. 


\section{Scanning electron microscopy (SEM) imaging}

Adult wing scales located in areas affected by the CRISPR experiment were individually picked with a needle and placed on carbon tape. All samples were sputter-coated with gold to increase conductivity and to reduce static surface charge. Samples were imaged using a JEOL JSM 6010LV Scanning Electron Microscope at 15-20kv.

\section{Acknowledgments}

This work was supported by a graduate fellowship to JW awarded by the Department of Biological Sciences, National University of Singapore, and by the National Research Foundation (NRF) Singapore, under its Investigatorship Programme (NRFNRFI05-2019-0006 Award).We thank Mr. BT Chin, Ms. Kuennie Lee, and Mr. Gan Gim Chuah (Entopia, Penang, Malaysia) for their support and for supplying some of the butterflies used in these experiments and Christopher Wheat (Stockholm University, Sweden) for providing the initial genomic sequences of DIl and sal in Pieris. canidia. We also thank Ms. Tong Yan (Centre for Biolmaging Sciences, National University of Singapore) for providing us help in the acquisition of the immunostaining images. 
Supplementary Files

Supplemental Table 1. A summary of all the primers used for in-situ hybridisations and CRISPR/Cas9 experiments in this chapter.

Primers ID

Sequence

Salm (P. canidia)

Forward Primer

TTTCAGTAGCAGGGCATGTG

Salm (P. canidia)

Reverse Primer

GATGGTGCACGTTGTGTTTC

Salm sgRNA 1

Dpp (P. canidia)

Forward Primer

Dpp ( $P$. canidia)

Reverse Primer

DIl (P. canidia)

Forward Primer

GAAATTAATACGACTCACTATAGGTGCGGTTGGCGGTTTCGG GAGTTTTAGAGCTAGAAATAGC

ACCACACCGCTACAGACCTC

GCACCACATTGTTCACTTCG

DIl (P. canidia)

Reverse Primer

AAGCGGTGAAAATCACAACC

DII sgRNA 1

TCTGGTAGAGCCAGGTACTGC

GAAATTAATACGACTCACTATAGGCTTAGATGAGACATTCGTG GGTTTTAGAGCTAGAAATAGC

DII sgRNA 2

GAAATTAATACGACTCACTATAGGGTAGATGGTGGAAGACTGC GGTTTTAGAGCTAGAAATAGC

Supplemental Table 2. Composition of buffers used in immunostaining reactions.

\begin{tabular}{|c|c|}
\hline \multicolumn{2}{|c|}{ 10X Phosphate-buffered saline (PBS) (In 500ml) } \\
\hline Dipotassium hydrogen phosphate $\left(\mathrm{K}_{2} \mathrm{HPO}_{4}\right)$ & $5.34 \mathrm{~g}$ \\
\hline Potassium dihydrogen phosphate $\left(\mathrm{KH}_{2} \mathrm{PO}_{4}\right)$ & $2.64 \mathrm{~g}$ \\
\hline Sodium chloride $(\mathrm{NaCl})$ & $40.9 \mathrm{~g}$ \\
\hline Milli-Q Water & To $500 \mathrm{ml}$ \\
\hline \multicolumn{2}{|l|}{ Fix Buffer (In 30 ml) } \\
\hline $500 \mathrm{mM}$ PIPES $\left(\mathrm{C}_{8} \mathrm{H}_{18} \mathrm{~N}_{2} \mathrm{O}_{6} \mathrm{~S}_{2}\right) \mathrm{pH} 6.9$ & $6 \mathrm{ml}$ \\
\hline $500 \mathrm{mM}$ EGTA $\left(\mathrm{C}_{14} \mathrm{H}_{24} \mathrm{~N}_{2} \mathrm{O}_{10}\right)$ pH 6.9 & $60 \mu \mathrm{l}$ \\
\hline $20 \%$ Triton $^{\mathrm{TM}} \mathrm{X}-100$ & $1.5 \mathrm{ml}$ \\
\hline 1M Magnesium sulfate $\left(\mathrm{MgSO}_{4}\right)$ & $60 \mu \mathrm{l}$ \\
\hline Milli-Q Water & $22.4 \mathrm{ml}$ \\
\hline $37 \%$ Formaldehyde $\left(\mathrm{CH}_{2} \mathrm{O}\right)$ & $\begin{array}{l}\text { Add } 55 \mu \mathrm{l} \text { per } 500 \\
\mu \mathrm{l} \text { of Fix Buffer }\end{array}$ \\
\hline \multicolumn{2}{|l|}{ Block Buffer (In $40 \mathrm{ml})$} \\
\hline $1 \mathrm{M}$ Tris-HCl pH 6.8 & $2 \mathrm{ml}$ \\
\hline $5 \mathrm{M}$ Sodium chloride $(\mathrm{NaCl})$ & $1.2 \mathrm{ml}$ \\
\hline $5 \mathrm{mg} / \mathrm{ml}$ Bovine Serum Albumin (BSA) & $0.2 \mathrm{~g}$ \\
\hline Milli-Q Water & $35.8 \mathrm{ml}$ \\
\hline \multicolumn{2}{|l|}{ Wash Buffer (In 200 ml) } \\
\hline $1 \mathrm{M}$ Tris-HCl pH 6.8 & $10 \mathrm{ml}$ \\
\hline $5 \mathrm{M}$ Sodium chloride $(\mathrm{NaCl})$ & $6 \mathrm{ml}$ \\
\hline $20 \%$ IGEPAL-CA630 & $5 \mathrm{ml}$ \\
\hline
\end{tabular}




\begin{tabular}{|l|l|}
\hline $1 \mathrm{mg} / \mathrm{ml}$ Bovine Serum Albumin (BSA) & $0.2 \mathrm{~g}$ \\
\hline Milli-Q Water & $179 \mathrm{ml}$ \\
\hline Mounting media & $20 \mathrm{mM}$ \\
\hline Tris-HCl pH 8.0 & $0.5 \%$ \\
\hline N-propyl gallate & $60 \%$ \\
\hline Glycerol &
\end{tabular}

\section{Supplemental Table 3. Composition of buffers used in in-situ hybridisation} reactions.

\begin{tabular}{|c|c|}
\hline \multicolumn{2}{|c|}{ 10X Phosphate-buffered saline (PBS) (In 500ml) } \\
\hline Dipotassium hydrogen phosphate $\left(\mathrm{K}_{2} \mathrm{HPO}_{4}\right)$ & $5.34 \mathrm{~g}$ \\
\hline Potassium dihydrogen phosphate $\left(\mathrm{KH}_{2} \mathrm{PO}_{4}\right)$ & $2.64 \mathrm{~g}$ \\
\hline Sodium chloride $(\mathrm{NaCl})$ & $40.9 \mathrm{~g}$ \\
\hline RNase-free water & To $500 \mathrm{ml}$ \\
\hline \multicolumn{2}{|c|}{ 1X Phosphate-Buffered Saline, 0.1\% Tween ${ }^{\circledR} 20$ Detergent (PBST) (In 50ml) } \\
\hline 1X Phosphate-buffered saline (PBS) & $50 \mathrm{ml}$ \\
\hline Tween $₫ 20$ & $50 \mu \mathrm{l}$ \\
\hline \multicolumn{2}{|c|}{ 20X Saline Sodium Citrate Buffer (SSC) (In 1000ml) } \\
\hline 3M Sodium Citrate $(\mathrm{NaCl})$ & $175.3 \mathrm{~g}$ \\
\hline Trisodium citrate $\left(\mathrm{Na}_{3} \mathrm{C}_{6} \mathrm{H}_{5} \mathrm{O}_{7}\right)$ & $88.2 \mathrm{~g}$ \\
\hline RNase-free water & $800 \mathrm{ml}$ \\
\hline \multicolumn{2}{|c|}{$\begin{array}{l}\text { Use } 1 \mathrm{M} \text { Hydrochloric acid }(\mathrm{HCl}) \text { to adjust } \mathrm{pH} \text { to } 7.0 \\
\text { Make up volume of buffer to } 1 \mathrm{~L} \text { using RNase-free water } \\
\text { Autoclave the buffer before use }\end{array}$} \\
\hline \multicolumn{2}{|c|}{ Pre-hybridization buffer (In 40ml) } \\
\hline Formamide $\left(\mathrm{CH}_{3} \mathrm{NO}\right)$ & $20 \mathrm{ml}$ \\
\hline 20X Saline Sodium Citrate Buffer (SSC) & $10 \mathrm{ml}$ \\
\hline Tween $\AA 20$ & $40 \mu \mathrm{l}$ \\
\hline RNase-free water & $10 \mathrm{ml}$ \\
\hline \multicolumn{2}{|l|}{ Hybridisation Buffer (In 40ml) } \\
\hline Formamide $\left(\mathrm{CH}_{3} \mathrm{NO}\right)$ & $20 \mathrm{ml}$ \\
\hline 20X Saline Sodium Citrate Buffer (SSC) & $10 \mathrm{ml}$ \\
\hline Tween® 20 & $40 \mu \mathrm{l}$ \\
\hline Salmon Sperm DNA & $40 \mu \mathrm{l}$ \\
\hline Glycine $\left(\mathrm{C}_{2} \mathrm{H}_{5} \mathrm{NO}_{2}\right)(100 \mathrm{mg} / \mathrm{ml})$ & $40 \mu \mathrm{l}$ \\
\hline RNase-free water & $10 \mathrm{ml}$ \\
\hline \multicolumn{2}{|l|}{ Block Buffer (In 50ml) } \\
\hline 1X Phosphate-buffered saline (PBS) & $50 \mathrm{ml}$ \\
\hline Tween $® 20$ & $50 \mu \mathrm{l}$ \\
\hline Bovine Serum Albumin (BSA) & $0.1 \mathrm{~g}$ \\
\hline \multicolumn{2}{|l|}{ Alkaline phosphatase buffer (In $20 \mathrm{ml})$} \\
\hline Tris Hydrochloride (Tris-HCl) $(\mathrm{pH} 8.0)$ & $2 \mathrm{ml}$ \\
\hline $5 \mathrm{M}$ Sodium chloride $(\mathrm{NaCl})$ & $400 \mu \mathrm{l}$ \\
\hline $200 \mathrm{mM}$ Magnesium chloride $\left(\mathrm{MgCl}_{2}\right)$ & $250 \mu \mathrm{l}$ \\
\hline Tween $\circledast 20$ & $20 \mu \mathrm{l}$ \\
\hline RNase-free water & To $20 \mathrm{ml}$ \\
\hline
\end{tabular}


Supplemental Table 4. Reaction mixture used for CRISPR/Cas9 experiments to knockout Distal-less and spalt in $P$. canidia and the observed hatching rate of injected embryos.

\begin{tabular}{|c|c|c|c|c|c|}
\hline \multicolumn{6}{|l|}{ Distal-less } \\
\hline $\begin{array}{l}\text { Concentration } \\
\text { of sgRNA: } \\
\text { Cas9 protein }\end{array}$ & $\begin{array}{c}\text { Eggs } \\
\text { Injected }\end{array}$ & Hatchlings & $\begin{array}{l}\text { Hatch } \\
\text { Rate }\end{array}$ & $\begin{array}{l}\text { No of adults } \\
\text { with mutant } \\
\text { phenotypes }\end{array}$ & $\begin{array}{c}\text { Description of } \\
\text { phenotypes observed }\end{array}$ \\
\hline $\begin{array}{c}100 \mathrm{ng} / \mu \mathrm{l}: \\
300 \mathrm{ng} / \mu \mathrm{l} \text { in } \\
10 \mu \mathrm{l}\end{array}$ & 357 & 70 & 19.6 & P & $\begin{array}{l}\text { Missing melanic scales } \\
\text { along wing margin in } \\
\text { both forewings and } \\
\text { hindwings }\end{array}$ \\
\hline \multicolumn{6}{|r|}{ 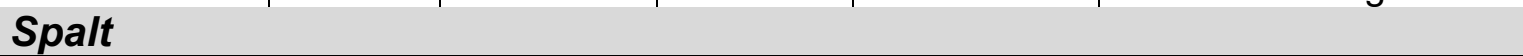 } \\
\hline $\begin{array}{l}\text { Concentration } \\
\text { of sgRNA: } \\
\text { Cas9 protein }\end{array}$ & $\begin{array}{l}\text { Eggs } \\
\text { Injected }\end{array}$ & Hatchlings & $\begin{array}{l}\text { Hatch } \\
\text { Rate }\end{array}$ & $\begin{array}{l}\text { No of adults } \\
\text { with mutant } \\
\text { phenotypes }\end{array}$ & $\begin{array}{c}\text { Description of } \\
\text { phenotypes observed }\end{array}$ \\
\hline $\begin{array}{c}300 \mathrm{ng} / \mu \mathrm{l}: \\
600 \mathrm{ng} / \mu \mathrm{l} \text { in } \\
10 \mu \mathrm{l}\end{array}$ & 575 & 98 & 17.0 & 9 & $\begin{array}{c}\text { Disruption of Cu2 vein, } \\
\text { missing melanic scales } \\
\text { in spot region and } \\
\text { along the wing margin } \\
\text { in forewings, lightened } \\
\text { spot markings }\end{array}$ \\
\hline
\end{tabular}

\section{$\underline{\text { Sequences }}$}

Probe sequence of $B$. anynana dpp used for in situ hybridisation.

GTTCTTCAACGTAAGCGGCGTACCGGCCGACGAGGTGGCGCGCGGCGCCGAC CTCTCGTTCCAACGAGCCGTCGGCACCACCGGCAGACAGAGACTGTTGTTGTA CGACGTGGTGCGCCCTGGCCGCCGCGGCCACTCCGAGCCGATCCTGCGGCTG CTGGACTCCGTTCCGCTCCGGCCCGGGGAGGGAATCGTCAACGCCGACGCTC TGGGAGCGGCGCGACGGTGGCTCAAAGAGCCCAAACATAATCACGGACTATTA GTGCGAGTGTTAGAAGAAGACGCCGCGAGTGCGAGCAGGGACGCGAAGTTCC CGCACGTGCGCGTGCGCAGACGCGTCACGGACGAGGAGGAGGAGTGGCGGA CGGCGCAGCCGCTGCTCATGCTGTACACGGAGGACGAGCGCGCGCGCGCGTC GCGGGAGACGAGCGAGCGGCTGACGCGCAGCAAGCGCGCGGCGCAGCGGCG GGGGCACCGCGCGCACCACCGCCGCAAGGAGGCGCGCGAGATCTGCCAGCG CCGCCCGCTGTTCGTCGACTTCGCGGACGTGGGCTGGAGCGACTGGATCGTG GCCCCGCACGGCTACGACGCGTACTACTGCCAGGGCGACTGCCCCTTCCCGC TGCCGGACCACCTCAACGGCACGAACCACGCGATAGTGCAGACTCTGGTCAAC TCAGTGAACCCCGCGACGGTGCCCAAAGCGTGCTGCGTGCCGACGCAACTCT CATCTATATCTATGTTATATATGGACGAAGTGAACAATGTGGTGCTTAAAAACTA TCAGGACATGATGGTGGTAGGCTGTGG

Probe sequence of $\boldsymbol{P}$. canidia dpp used for in situ hybridisation.

ACCACACCGCTACAGACCTCGACGATCGCTTCCCTCAGGAGCATCGCTTTCGC CTATATTTCAACATAAGTGGCGTACCTGGCGACGAAGTCGCTCGAGGCGCGGA TGTCACCTTTCAACGCGCCGTCGGTGTCACCGGCACACAGAGGCTGCTGCTGT ACGACGTGGTGCGCCCGGGCAGACGAGGAAAGAGCGAACCCATTTTGAGACT 
CCTCGATTCCATTCCGCTCCGACCCGGCCAAGGTTCGGTCGCGGCCGACGCC CTCAGCGCGGCGAGAAGGTGGCTCAAGGAACCGCAACATAATCATGGCCTATT AGTGCGCGTCATAGACGATACCGTAGGCAATGAAAGTGTAAAATTTCCACATAT TCGCGTCCGACGGCGCGCTACAGACGAGCACGAGGAATGGAGCGCCATCCAG CCTCTGCTGATGCTTTACACGGAGGATGCGAGAGCGAGAACGGCTCGGGAGC GTGGAGAGTCGTCGCTGACGAGAAATAAGAGAGCGACGCAGCGGAAGGGCCA CCGGCCTCACCACAGGCGTAAGGAGGCGCGGGAGATCTGCCAGAGGCGCCCC CTGTTCGTGGATTTCGCGGACGTGGGTTGGAGTGACTGGATTGTCGCCCCCCA GGGCTACGAAGCCTACTATTGCCAGGGCGATTGCCCCTTCCCATTAGCCGATC ACCTCAATGGTACGAACCATGCGATTGTGCAGACTTTAGTGAACTCAGTGAATC CGGCCGCGGTGCCGAAGGCGTGTTGTGTGCCGACGCAACTTTCCCCTATATCT ATGTTGTATATGGACGAAGTGAACAATGTGGTGC

\section{Sequence of $\boldsymbol{P}$. canidia Distal-less and site of CRISPR targets.}

ATGGAGCGAGAGGCTCACAAAGCGGTGAAAATCACAACCAAGCATCCGAAATC CCTCAAAATTACCCGAATTCAATCCCCAAACACAAAACCGGCCACGCTGAGTTT CTCAGATCCCTTCGGGCCTCCCCAGTCCGCGGACGGGGGGGGCCCATCAACC CCCCAACCAGCCATGACCACCCAAGAGGCGTTGGAGCACCAGCACCACCATTT GGGGGGCACGCAAACCCCCCACGACATCTCGAACTCCGCCAATTCCACCCCCA CGAATGTCTCATCTAAGTCCGCGTTCATCGAGCTTCAACAGCATGGGTATGGGT TCAAGGGGGGCTACCAGCATCCCCACCATTTTGGGAGTCCGGGGGGACAACA GAACCCTCATGAAGCGTCGGGATTCCCCAGTCCTAGATCGTTAGGTTACCCCTT CCCTCCCATGCACCAGAATACCTATGGTTATCATTTAGGTTCCTATGCCCCCCA ATGCGCGAGTCCTCCTAAAGATGAAAAATGTGGCCTCTCCGATGACCCCGGCT TACGGGTAAATGGAAAGGGCAAGAAGATGAGGAAACCCCGCAGTCTTCCACCA TCTACTCAGCTTCAGCAGCTTAATAGGCGGTTTCAAAGAACGCAGTACCTGGCT CTACCAGAGAGAGCAGAGCTCGCGGCTAGCTTAGGATTAACGCAGACACAGGT AAGTGGCTTAACAATAAAGAAA

\section{Sequence of $\boldsymbol{P}$. canidia spalt-major and site of CRISPR targets.}

TTTCAGTAGCAGGGCATGTGACACTAGAAGCACTTCAAAATACGAAGGTTGCCG TAGCACAATTTGCTGCAACGGCAATGGCCAATAACGCCAACAATGAAGCTGCTT TACATGAGCTGGCAGTCTTACAGAGTACGTTGTTCACATTGCAGCATCAGCAAG TGTTTCAACTTCAATTAATAAGACAGTTGCAAAATCAATTATCATTAACGAGAAGA AAAGATGATCAACCACCAAGTCCATCGCCGGTTGAACAAGAAGCGACCGCTCC ATCGACTCCGGTTCGATCACCATCACCGCCTCGTCCGCCACGGGAGCCATCTC CTGCTGCACCAACTCCTCCCAGTAGCCAAAGCTTGCCATCGACCCACTCGCATA TCACACCTAAAATTGAACCGATTTCCATCCCGAAACCGCCAACCGCATCTCCAC CTATGATGTCACATCCACCCTACAGCTCCATTTCGTCTTCATTAGCTTCTTGTAT TATCACGAATAATGATCCTCCACCGTCCCTTAATGAACCAAATACACTTGAAATG CTACAGAAGCGAGCGCAAGAAGTACTTGACAATGCATCACAAGGTTTATTAGCA AATAATTTAGCCGACGAACTGGCGTTTAGAAAATCTGGTAAAATGTCACCCTATG ATGGAAAAAGTGGAGGTAGAAATGAACCGTTTTTCAAGCACAGATGCAGATATT 
GTGGAAAAGTTTTTGGAAGTGACTCTGCACTCCAAATACACATACGGTCACATA CAGGCGAGCGACCTTTTAAATGTAATGTTTGTGGATCAAGATTCACAACAAAAG GAAACCTTAAAGTCCACTTTCAAAGGCATACATCTAAGTTTCCACACGTAAAAAT GAACCCGAACCCAGTGCCAGAACACTTAGACAAATACCACCCCCCACTACTTGC ACAACTATCTCCGGGGCCAATTCCAGGGATGCCCCCACATCCTCTTCAGTTTCC TCCTGGCGCACCAGCTCCATTTCCGCCAAGCTTGCCATTATACAGACCAACGCA TCATGATTTACTTCCCCCTCGCCCACTCGGTGACAAGACACTTCCACCACACCC ATTATTTACAATGAGAGAAGAGCAAGATGCACCTGCAGATTTAAGCAAACCTTCT GCACCCAGCCCATCAAGATTAACATCTGAGATGTTTAAGTCTGAGCCACAAGAC GATGAGAGCCAACGCGATTCTAGTTTTGAAGAAACTGACCGAATATCACCTAAG CGAGAGCCAGAGGAGAATGAACCCGTACATGACGCAGAACAAGATCGATATCC ATCCACTTCACCCTACGATGACTGCAGTATGGACTCGAAGTATAGTAATGAAGA CCAAATCGGAAGAGAGAGCCCTCACGTGAAGCCGGATCCTGATCAACCGGAAA ATCTTTCAAGTAAGAATCGACCGGGCAGCAACGATAACTCATGGGAAAGTTTAA TTGAAATAACGAAAACTTCAGAAACATCCAAGCTACAGCAATTAGTTGACAATAT TGACAATAAGGTGTCTGATCCAAATGAATGTATTGTGTGTCATCGTGTTCTTTCT TGTAAAAGTGCTTTGCAAATGCACTACCGTACTCACACCGGTGAGAGACCATTT CGTTGTAAATTATGTGGTCGAGCATTTACTACTAAAGGAAATCTTAAAACCCATA TGGGTGTTCACCGCATTAAACCTCCTTCTCAAATTTTACACCAATGTCCTGTTTG CCATAGAAGGTTTCCTGATCCGAATATTCTCCATCAACACATTCGAACACACACA AGCGACCGTTACAGTACCCCTTTCGATCAATTAATGATTCGCGACTTAACCGAC AGTCAATCAATAAGCAATAATGACTCTGAATATGTGCGTGGAAACACAACGTGC ACCATC 


\section{$\underline{\text { References }}$}

Banerjee, D. T., \& Monteiro, A. (2018). CRISPR-Cas9 Mediated Genome Editing in Bicyclus anynana Butterflies. Methods and Protocols, 1(2). https://doi.org/10.3390/mps1020016

Banerjee, T. D., \& Monteiro, A. (2020a). Dissection of Larval and Pupal Wings of Bicyclus anynana Butterflies. Methods and Protocols, 3(1), 5. https://www.mdpi.com/2409$\underline{9279 / 3 / 1 / 5}$

Banerjee, T. D., \& Monteiro, A. (2020b). Molecular mechanism underlying venation patterning in butterflies. bioRxiv.

Banerjee, T. D., Shan, S. K., \& Monteiro, A. (2021). optix is involved in eyespot development via a possible positional information mechanism. bioRxiv.

Barrio, R., \& de Celis, J. F. (2004). Regulation of spalt expression in the Drosophila wing blade in response to the Decapentaplegic signaling pathway. Proceedings of the National Academy of Sciences, 101(16), 6021-6026.

Bhardwaj, S., Jolander, L. S.-H., Wenk, M. R., Oliver, J. C., Nijhout, H. F., \& Monteiro, A. (2020). Origin of the mechanism of phenotypic plasticity in satyrid butterfly eyespots. Elife, 9, e49544.

Brunetti, C. R., Selegue, J. E., Monteiro, A., French, V., Brakefield, P. M., \& Carroll, S. B. (2001). The generation and diversification of butterfly eyespot color patterns. Current Biology, 11(20), 1578-1585.

Chan, I. Z., Ngan, Z. C., Naing, L., Lee, Y., Gowri, V., \& Monteiro, A. (2021). Predation favours Bicyclus anynana butterflies with fewer forewing eyespots. Proceedings of the Royal Society B, 288(1951), 20202840.

Cohen, B., Simcox, A. A., \& Cohen, S. M. (1993). Allocation of the thoracic imaginal primordia in the Drosophila embryo. Development, 117(2), 597-608.

Connahs, H., Tlili, S., van Creij, J., Loo, T. Y., Banerjee, T. D., Saunders, T. E., \& Monteiro, A. (2019). Activation of butterfly eyespots by Distal-less is consistent with a reactiondiffusion process. Development, 146(9).

De Bona, S., Valkonen, J. K., López-Sepulcre, A., \& Mappes, J. (2015). Predator mimicry, not conspicuousness, explains the efficacy of butterfly eyespots. Proceedings of the Royal Society B: Biological Sciences, 282(1806), 20150202.

de Celis, J. F., Barrio, R., \& Kafatos, F. C. (1996). A gene complex acting downstream of dpp in Drosophila wing morphogenesis. Nature, 381(6581), 421-424.

Estella, C., McKay, D. J., \& Mann, R. S. (2008). Molecular integration of wingless, decapentaplegic, and autoregulatory inputs into Distalless during Drosophila leg development. Developmental Cell, 14(1), 86-96.

Finkbeiner, S. D., Briscoe, A. D., \& Reed, R. D. (2014). Warning signals are seductive: relative contributions of color and pattern to predator avoidance and mate attraction in Heliconius butterflies. Evolution, 68(12), 3410-3420. 
bioRxiv preprint doi: https://doi.org/10.1101/2021.09.02 458688; this version posted September 2 2021. The copyright holder for this

Fordyce, J., Nice, C., Forister, M., \& Shapiro, A. (2002). The significance of wing pattern diversity in the Lycaenidae: mate discrimination by two recently diverged species. Journal of evolutionary biology, 15(5), 871-879.

Galant, R., Skeath, J. B., Paddock, S., Lewis, D. L., \& Carroll, S. B. (1998). Expression pattern of a butterfly achaete-scute homolog reveals the homology of butterfly wing scales and insect sensory bristles. Current Biology, 8(14), 807-813.

Ghiradella, H., Aneshansley, D., Eisner, T., Silberglied, R. E., \& Hinton, H. E. (1972). Ultraviolet reflection of a male butterfly: interference color caused by thin-layer elaboration of wing scales. Science, 178(4066), 1214-1217.

Ho, S., Schachat, S. R., Piel, W. H., \& Monteiro, A. (2016). Attack risk for butterflies changes with eyespot number and size. Royal Society Open Science, 3(1), 150614.

Iwasaki, M., Ohno, Y., \& Otaki, J. M. (2017). Butterfly eyespot organiser: in vivo imaging of the prospective focal cells in pupal wing tissues. Scientific Reports, 7(1), 1-10.

Kingsolver, J. G. (1985). Thermoregulatory significance of wing melanisation in Pieris butterflies (Lepidoptera: Pieridae): physics, posture, and pattern. Oecologia, 66(4), 546-553.

Labun, K., Montague, T. G., Krause, M., Torres Cleuren, Y. N., Tjeldnes, H., \& Valen, E. (2019). CHOPCHOP v3: expanding the CRISPR web toolbox beyond genome editing. Nucleic acids research, 47(W1), W171-W174.

Merilaita, S., Vallin, A., Kodandaramaiah, U., Dimitrova, M., Ruuskanen, S., \& Laaksonen, T. (2011). Number of eyespots and their intimidating effect on naive predators in the peacock butterfly. Behavioral Ecology, 22(6), 1326-1331.

Monteiro, A., Chen, B., Ramos, D. M., Oliver, J. C., Tong, X., Guo, M., Wang, W.-K., Fazzino, L., \& Kamal, F. (2013). Distal-less regulates eyespot patterns and melanisation in Bicyclus butterflies. J Exp Zool B Mol Dev Evol, 320. https://doi.org/10.1002/jez.b.22503

Monteiro, A., Glaser, G., Stockslager, S., Glansdorp, N., \& Ramos, D. (2006). Comparative insights into questions of lepidopteran wing pattern homology. BMC Developmental Biology, 6(1), 1-13.

Murugesan, S. N., Connahs, H., Matsuoka, Y., das Gupta, M., Huq, M., Gowri, V., Monroe, S., Deem, K. D., Werner, T., \& Tomoyasu, Y. (2021). Butterfly eyespots evolved via co-option of the antennal gene-regulatory network. bioRxiv.

Oliver, J. C., Beaulieu, J. M., Gall, L. F., Piel, W. H., \& Monteiro, A. (2014). Nymphalid eyespot serial homologues originate as a few individualized modules. Proceedings of the Royal Society B: Biological Sciences, 281(1787), 20133262.

Oliver, J. C., Tong, X. T., Gall, L. F., Piel, W. H., \& Monteiro, A. (2012, 2012//). A single origin for nymphalid butterfly eyespots followed by widespread loss of associated gene expression. PLoS Genet, 8. https://doi.org/10.1371/journal.pgen.1002893

Özsu, N., Chan, Q. Y., Chen, B., Gupta, M. D., \& Monteiro, A. (2017). Wingless is a positive regulator of eyespot color patterns in Bicyclus anynana butterflies. Developmental Biology, 429(1), 177-185. 
bioRxiv preprint doi: https://doi.org/10.1101/2021.09.02 458688; this version posted September 2 2021. The copyright holder for this

Panganiban, G. (2000). Distal-less function during Drosophila appendage and sense organ development. Developmental dynamics: an official publication of the American Association of Anatomists, 218(4), 554-562.

Prudic, K. L., Stoehr, A. M., Wasik, B. R., \& Monteiro, A. (2015). Eyespots deflect predator attack increasing fitness and promoting the evolution of phenotypic plasticity. Proceedings of the Royal Society B: Biological Sciences, 282(1798), 20141531.

Reed, R. D., Selegue, J. E., Zhang, L., \& Brunetti, C. R. (2020). Transcription factors underlying wing margin color patterns and pupal cuticle markings in butterflies. EvoDevo, 11, 1-10.

Reed, R. D., \& Serfas, M. S. (2004). Butterfly wing pattern evolution is associated with changes in a Notch/Distal-less temporal pattern formation process. Current Biology, 14(13), 1159-1166.

Robertson, K. A., \& Monteiro, A. (2005). Female Bicyclus anynana butterflies choose males on the basis of their dorsal UV-reflective eyespot pupils. P Roy Soc London B Bio, 272. https://doi.org/10.1098/rspb.2005.3142

Saenko, S. V., Marialva, M. S., \& Beldade, P. (2011). Involvement of the conserved Hox gene Antennapedia in the development and evolution of a novel trait. EvoDevo, 2(1), $1-10$.

Silberglied, R. E. (1984). Visual communication and sexual selection among butterflies. The biology of butterflies.

Silberglied, R. E., \& Taylor, O. R. (1978). Ultraviolet reflection and its behavioral role in the courtship of the sulfur butterflies Colias eurytheme and C. philodice (Lepidoptera, Pieridae). Behavioral Ecology and Sociobiology, 3(3), 203-243.

Stavenga, D., Stowe, S., Siebke, K., Zeil, J., \& Arikawa, K. (2004). Butterfly wing colours: scale beads make white pierid wings brighter. Proceedings of the Royal Society of London. Series B: Biological Sciences, 271(1548), 1577-1584.

Stevens, M. (2005). The role of eyespots as anti-predator mechanisms, principally demonstrated in the Lepidoptera. Biological Reviews, 80(4), 573-588.

Stevens, M., Hopkins, E., Hinde, W., Adcock, A., Connolly, Y., Troscianko, T., \& Cuthill, I. C. (2007). Field experiments on the effectiveness of 'eyespots' as predator deterrents. Animal Behaviour, 74(5), 1215-1227.

Stoehr, A. M., \& Goux, H. (2008). Seasonal phenotypic plasticity of wing melanisation in the cabbage white butterfly, Pieris rapae L.(Lepidoptera: Pieridae). Ecological Entomology, 33(1), 137-143.

Stoehr, A. M., Walker, J. F., \& Monteiro, A. (2013). Spalt expression and the development of melanic color patterns in pierid butterflies. EvoDevo, 4(1), 1-11.

Uésugi, K. (1996). The adaptive significance of Batesian mimicry in the swallowtail butterfly, Papilio polytes (Insecta, Papilionidae): associative learning in a predator. Ethology, 102(5), 762-775.

Wilts, B. D., Pirih, P., \& Stavenga, D. G. (2011). Spectral reflectance properties of iridescent pierid butterfly wings. Journal of Comparative Physiology A, 197(6), 693-702. 
bioRxiv preprint doi: https//doi org/10.1101/2021 09 02 458688. this version posted September 2 2021. The copyright holder for this preprint (which was not certified by peer review) is the author/funder, who has granted bioRxiv a license to display the preprint in perpetuity. It is made available under aCC-BY 4.0 International license.

Wilts, B. D., Wijnen, B., Leertouwer, H. L., Steiner, U., \& Stavenga, D. G. (2017). Extreme refractive index wing scale beads containing dense pterin pigments cause the bright colors of pierid butterflies. Advanced Optical Materials, 5(3), 1600879.

Zhang, L., Mazo-Vargas, A., \& Reed, R. D. (2017). Single master regulatory gene coordinates the evolution and development of butterfly color and iridescence. Proceedings of the National Academy of Sciences, 114(40), 10707-10712.

Zhang, L., \& Reed, R. D. (2016). Genome editing in butterflies reveals that spalt promotes and Distal-less represses eyespot colour patterns. Nature Communications, 7(1), 17. 